Proceedings of the International Symposium on Physics of Materials (ISPMA 14), September 10-15, 2017, Prague

\title{
High-Temperature Stability of Phases in Boron Containing Co-Re Alloys for Gas Turbine Applications
}

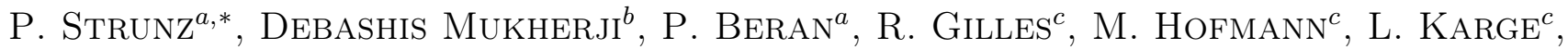 \\ J. RÖSLER ${ }^{b}$ AND G. FARKAS ${ }^{d}$ \\ ${ }^{a}$ Nuclear Physics Institute ASCR, 25068 Rež near Prague, Czech Republic \\ ${ }^{b}$ Technische Universität Braunschweig, Institut für Werkstoffe, Langer Kamp 8, 38106 Braunschweig, Germany \\ ${ }^{c}$ Technische Universität München, Heinz Maier-Leibnitz Zentrum (MLZ), \\ Lichtenbergstr. 1, 85747 Garching, Germany \\ ${ }^{d}$ Department of Physics of Materials, Faculty of Mathematics and Physics, Charles University, Ovocný trh 5, Prague
}

\begin{abstract}
Co-Re-based alloys are candidates for high-temperature applications in gas turbines. The addition of boron largely increases their ductility. The stability of the Co-solid solution matrix and of the strengthening TaC minority phase at the foreseen alloy operation temperatures $\left(\geq 1200^{\circ} \mathrm{C}\right)$, potentially influenced by the presence of boron, has to be considered. The hcp to fcc transformation of the Co-solid solution matrix and the TaC minority phase evolution was thus investigated in $\mathrm{Co}-\mathrm{Re}-\mathrm{Ta}-\mathrm{C}$ alloy with varying boron addition by in situ neutron diffraction at temperatures up to $1500^{\circ} \mathrm{C}$ in high vacuum furnace. The neutron diffraction showed that the boron addition has no significant influence on $\mathrm{TaC}$ volume fraction during heating to high temperatures. In $0,0.1$, and 0.4 at.\% $\mathrm{B}$ alloys, a strong decrease of the $\mathrm{TaC}$ volume fraction was observed above $1300^{\circ} \mathrm{C}$. Nevertheless, TaC has significant volume fraction up to that temperature and, therefore, can be effective for strengthening. The measurements further showed that while a small amount of boron addition ( 0.1 at.\% B) has no influence on the matrix transformation and its hysteresis, a large boron addition $(0.4$ at.\% B) influences the matrix transformation temperature significantly (lowers it by about $100 \mathrm{~K}$ ) and, moreover, boron promotes massive Co sublimation at very high temperatures $\left(\geq 1470{ }^{\circ} \mathrm{C}\right.$ ). Further, re-appearance of the hcp phase around $1400^{\circ} \mathrm{C}$ in 0.4 at.\% B alloy was observed and explained by a slow sublimation of Co in high vacuum. It is not a problem from the technological point of view as vacuum is not a turbine operation condition, and as the high-temperature components are regularly protected by a coating.
\end{abstract}

DOI: 10.12693/APhysPolA.134.829

PACS/topics: 61.05.fg, 61.66.Dk

\section{Introduction}

Co-Re-based alloys [1-3] containing boron are promising candidates for high-temperature applications in future gas turbines. Boron largely increases the ductility [4] and is thus beneficial for the Co-Re applications. On the other hand, the stability of the Co-solid solution matrix and also the minority phases at the foreseen alloy operation temperatures $\left(\geq 1200^{\circ} \mathrm{C}\right)$, which could be influenced by the presence of boron, is also an important concern for the alloy development [3]. Therefore, the influence of boron addition on $\mathrm{Co}-\mathrm{Re}-\mathrm{Cr}$ alloy stability and phase transformations at high temperatures (HT) were investigated by neutron diffraction (ND) in the past $[5,6]$.

Neutron diffraction has proved to be a valuable tool to study both minority phase stability [7-13] as well as the matrix transformations in situ at high temperatures [1416]. In Co-Re alloys, neutron measurements showed that the low temperature Co-solid solution matrix (hexagonal close packed phase - hcp, alternatively denoted $\varepsilon$ ) undergoes an allotropic transformation to a face centered

*corresponding author; e-mail: strunz@ujf.cas.cz structure (fcc or $\gamma$ ) structure at high temperatures [14]. On cooling, the reverse transformation occurs, however, this transformation shows a broad hysteresis in dependence on the alloy composition $[8,14,15]$.

For boron-containing Co-Re alloy with chromium $\left(\mathrm{Co}^{-}\right.$ $17 \operatorname{Re}-23 \mathrm{Cr}$, at.\%), it was found [5] that the increase of the boron concentration changes significantly - but not monotonically - the hcp $\rightarrow$ fcc matrix transformation temperature of the alloy. The reason is an interplay between the amount of boron in the matrix and the amount of sigma phase ( $\sigma$ phase is of $\mathrm{Cr}_{2} \mathrm{Re}_{3}$-type tetragonal structure with Sp. Gp. no. 136) which binds the hcpstabilizing element Re. Moreover, increasing the boron concentration also lowers the temperature at which sublimation of Co and/or Cr occurs from the matrix, followed by appearance of second and third matrix hcp phases [6]. The presence of these additional hcp phases, which appear at the highest temperatures $\left(>1430^{\circ} \mathrm{C}\right)$ used for the tests, is caused by the Co sublimation from the sample surface. In the view of the alloy development, this effect is not detrimental, as the temperature for the evaporation starts significantly above the foreseen operation temperature of the alloy. Moreover, Co-Re alloy components will be generally protected by thermal barrier or oxidation resistance coatings. 
Nevertheless, other aspects of boron influence on hightemperature stability of $\mathrm{Co}-\mathrm{Re}$ alloys have to be also considered and examined. The stability of potentially strengthening minority phases in Co-Re alloys not containing boron at prospective operation temperatures $\left(\geq 1200^{\circ} \mathrm{C}\right)$ was investigated in earlier in situ neutron scattering experiments $[9,14-16]$. Due to its stability, tantalum carbide (TaC) was found to be promising as a strengthening phase at high temperatures [13]. The TaC phase is a strongly non-stoichiometric interstitial compound, which exists over a wide composition range in the binary $\mathrm{Ta}-\mathrm{C}$ system, and its stability at high temperatures $\left(>1200^{\circ} \mathrm{C}\right)$ in $\mathrm{Co}-\mathrm{Re}$ alloys has been demonstrated through earlier neutron-scattering measurements $[9,12,14,16]$.

In the present study, we investigated the influence of boron addition on the hcp-fcc transformation and on the TaC stability. The alloy with no chromium was selected for this study because such alloy does not contain any sigma phase. Further, there are neither Cr-rich borides [5] nor $\mathrm{Cr}$ carbides $\left(\mathrm{Cr}_{23} \mathrm{C}_{6}\right)$ which could appear in the alloys containing chromium and were observed in other studied $\mathrm{Co}-\mathrm{Re}$ alloy variants. These facts simplify the investigated alloy system. Only $\mathrm{TaC}$ carbides together with hcp and fcc matrix phases are to be considered for the evaluation of ND data.

\section{Experimental}

\subsection{Alloys}

Several Co-17Re samples with Ta and C, and with varying boron concentration (0, 0.1, 0.4 at.\% of boron), were investigated. Samples were prepared by vacuum induction melting at approximately $1900 \mathrm{~K}\left(1623^{\circ} \mathrm{C}\right)$ thereby dissolving all constituents (Re, Ta, C and B) in a short time, producing a homogeneous melt. Then, the alloys were cast into blocks. Prior to the in situ neutron diffraction experiment, the samples were subjected to a 3 step standard homogenization heat treatment (ST) in vacuum, which consisted of the following steps: $1623 \mathrm{~K}\left(1350^{\circ} \mathrm{C}\right) / 5 \mathrm{~h}+1673 \mathrm{~K}\left(1400^{\circ} \mathrm{C}\right) / 5 \mathrm{~h}$ $+1723 \mathrm{~K}\left(1450^{\circ} \mathrm{C}\right) / 5 \mathrm{~h}$. The alloy was subsequently cooled in 5 bar argon gas atmosphere to room temperature (RT) with the average rate $80 \mathrm{~K} / \mathrm{min}$.

The samples for neutron diffraction were either of cylindrical shape (6 $\mathrm{mm}$ diameter and $30 \mathrm{~mm}$ long) or of plate-like shape (thickness about $1 \mathrm{~mm}$, size $12 \times$ $12 \mathrm{~mm}^{2}$ ). The samples measured in situ at HT using ND

The used samples with composition and heat treatment are listed in Table I. For all the investigated samples, the alloy composition had the $\mathrm{C} / \mathrm{Ta}$ ratio $y$ equal to 0.9 .

\subsection{Neutron diffraction}

The samples were mounted in a vacuum hightemperature furnace for in situ neutron diffraction measurements at high temperatures up to $1500^{\circ} \mathrm{C}$. The used maximum temperatures of in situ thermal cycles are listed in Table I for the individual samples.

The diffractometer Stress-Spec [17] at FRM II, Garching, Germany, was used for the measurements. The instrument is equipped with a two-dimensional position sensitive detector and the experiment was performed with neutron wavelength of $0.164 \mathrm{~nm}$. The diffractograms were collected predominantly in a limited angular range $(2 \theta)$ between $42.2^{\circ}$ and $65.8^{\circ}$ (which contains the important reflections) during the temporary stops (25 min, two detector positions) at a particular temperature during heating or cooling. Nevertheless, each sample was also measured in the full accessible angular $2 \theta$ range between $42^{\circ}$ and $105^{\circ}$ at room temperature (RT) before and after the in situ cycle, as well as at selected temperatures during the thermal cycle.

It had been known from the previous HT experiments with Co-Re alloys that fine grained hcp transforms to fcc at high temperatures and the grains quickly coarsen (during the opposite transformation from fcc to hcp on cooling, nevertheless, the coarse grained fcc eventually transforms to fine hcp laths). Therefore, angular oscillation of the whole furnace with sample inside within $\pm 5^{\circ}$ was needed for obtaining rather smooth Debye-Scherrer rings (i.e. without large spots in the diffraction pattern) for the fcc peaks on the $2 \mathrm{D}$ position sensitive detector.

\section{Results and discussion}

\subsection{Alloy with 0.1 at.\% boron addition}

Figure 1 shows the evolution of diffraction profiles with temperature in the first thermal cycle measured in a limited angular diffraction angle $(2 \theta)$ range for the sample CoRe-TaC-09y-01B (i.e. 0.1 at.\% B). The sample was heated to the highest temperature of $1500^{\circ} \mathrm{C}$. The evolution of peaks from different phases with temperature is mapped in color (blue to red, where blue depicts low and red high intensity). The ND measurement clearly showed transformation of hcp to fcc Co phase at temperatures above $1100^{\circ} \mathrm{C}$ (see the hcp 101 and fcc 200 peaks evolution in Fig. 1).

TABLE I

\begin{tabular}{l|c|c|c|c|c|l}
\hline \hline \multirow{2}{*}{ Sample name } & \multicolumn{7}{|c|}{ Composition in at.\% } & \multirow{2}{*}{ In situ thermal cycle(s) } \\
\cline { 2 - 6 } & Co & Re & Ta & C & B & \\
\hline CoRe-TaC-09y-00B & 80.72 & 17 & 1.2 & 1.08 & no & up to $1500^{\circ} \mathrm{C}$ \\
CoRe-TaC-09y-01B & 80.62 & 17 & 1.2 & 1.08 & 0.1 & up to $1500^{\circ} \mathrm{C}$, two cycles \\
CeRe-TaC-09y-04B & 80.32 & 17 & 1.2 & 1.08 & 0.4 & up to $1500{ }^{\circ} \mathrm{C}, 80$ min hold \\
CeRe-TaC-09y-04B_No.1 & 80.32 & 17 & 1.2 & 1.08 & 0.4 & up to $1470^{\circ} \mathrm{C}, 17 \mathrm{~h}$ hold \\
CeRe-TaC-09y-04B_No.2 & 80.32 & 17 & 1.2 & 1.08 & 0.4 & three cycles up to $1390^{\circ} \mathrm{C}$
\end{tabular}




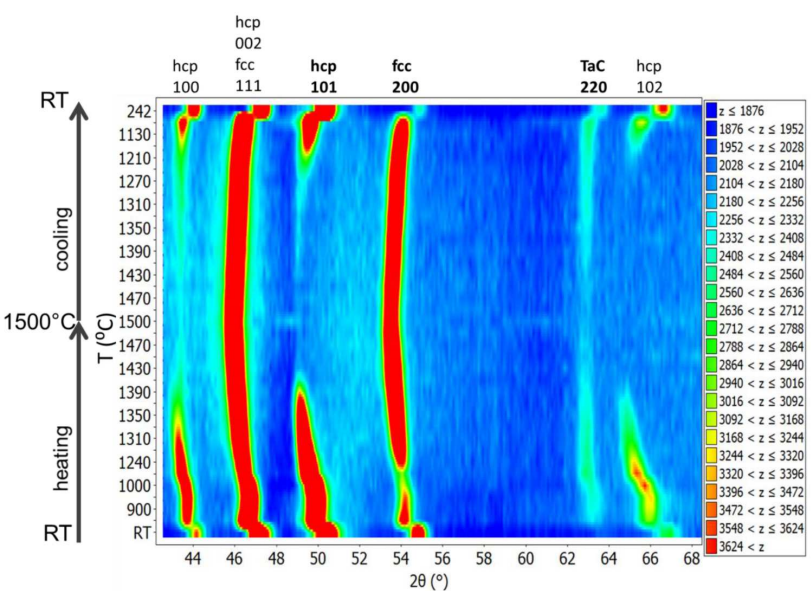

Fig. 1. Temperature dependence of the diffractograms for the 0.1 at.\% B sample CoRe-TaC-09y-01B (first thermal cycle). The important reflections are marked. The scale on the left denotes the temperature on heating (bottom part) and cooling (upper part). The color-map intensity levels (the color range shown in the right) were selected in such a way that also the weaker reflections are clearly visible.

The result of the Rietveld refinement of phase content by FullProf software [18] for the CoRe-TaC-09y-01B sample is depicted in Fig. 2 for two applied thermal cycles. Upper part of the figure shows hcp and fcc matrix phases evolution while the bottom part shows $\mathrm{TaC}$ content.

During the initial temperature increase and when holding at $900^{\circ} \mathrm{C}$, there is a strong decrease of fcc phase volume fraction and - at the same time - an increase of hcp matrix phase volume fraction. It indicates that argon quenching after ST caused a metastable state characterized by an excess of fcc matrix phase in the matrix. This metastable fcc ( $\gamma$ phase) is first transformed to the stable hcp ( $\varepsilon$ phase) on in situ heating to $900{ }^{\circ} \mathrm{C}$. Consequently, there is also a strong fcc decrease when comparing the fcc content before and after the first thermal cycle. One important factor is that the cooling during the in situ cycle in the furnace installed at StressSpec was much slower than in the furnace used for laboratory ST heat treatment.

It can be also deduced that one cycle is sufficient to achieve equilibrium phase content at RT as nearly no change in the fcc and hcp fractions is observed after the second cycle when compared with the content after the first cycle.

The hcp phase transforms fully to fcc at $1420^{\circ} \mathrm{C}$. On cooling, it starts to transform back to hcp at $1260^{\circ} \mathrm{C}$, which indicates a hysteresis of $160 \mathrm{~K}$ of the matrix transformation.

In addition, second thermal cycle with identical parameters as the first one was applied on the CoRe-TaC09y-01B sample. Except for reaching equilibrium phase content of the matrix phase at relatively low temperature of $900^{\circ} \mathrm{C}$, the first and the second cycles look very similar for this sample (no shift of transformation temperature or change in hysteresis - see Fig. 2).

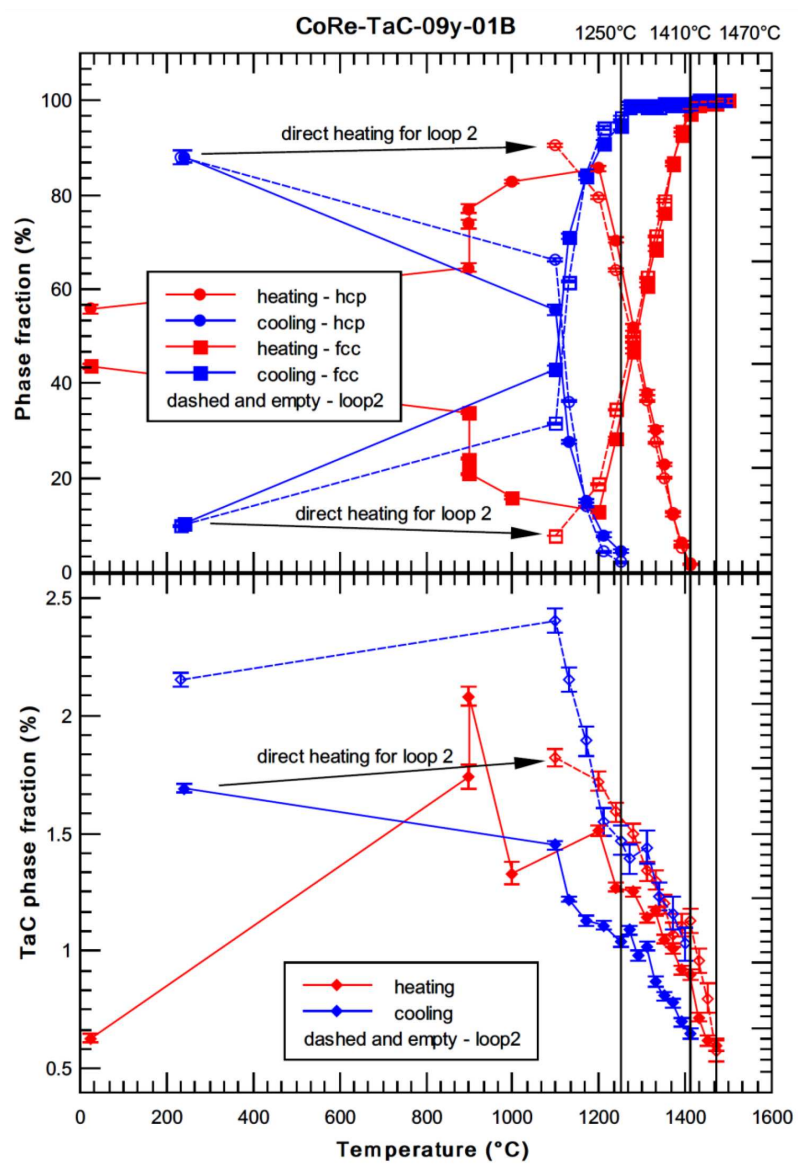

Fig. 2. Temperature dependence of the phase volume fraction for the 0.1 at.\% B sample CoRe-TaC-09y-01B for two thermal cycles. Upper part of the figure shows hcp and fcc matrix phases while the bottom part show $\mathrm{TaC}$ content.

At RT after the first cycle not only equilibrium was achieved (connected with higher hcp matrix content), but also the $\mathrm{TaC}$ content significantly increased. Further, $\mathrm{TaC}$ content still slightly increased after the second cycle (Fig. 2) and reached 2.2\%.

It can be seen from Fig. 2 that there was a strong decrease of $\mathrm{TaC}$ volume fraction above $1300{ }^{\circ} \mathrm{C}$. This effect is connected with the decrease of hcp matrix phase and indicates that hcp matrix has larger affinity for $\mathrm{TaC}$ carbides than fcc matrix. It is due to the fact that Ta and $\mathrm{C}$ are fcc stabilizers [19] and there can thus be more $\mathrm{Ta}$ and $\mathrm{C}$ dissolved in fec than in hep matrix.

\subsection{Alloy with 0.4 at.\% boron addition}

Figure 3 displays the evolution of diffraction profiles with temperature in the thermal cycle up to $1500^{\circ} \mathrm{C}$ for the sample CoRe-TaC-09y-04B (i.e. 0.4 at.\% B). Although the evolution of phases at the beginning of the thermal cycle is rather similar to the 0.1 at.\% B sample (i.e. the fcc-hcp content is equilibrated at $900^{\circ} \mathrm{C}$ ), the evolution of matrix phases at higher temperatures is significantly different. It is clearly seen from Fig. 3 that the 


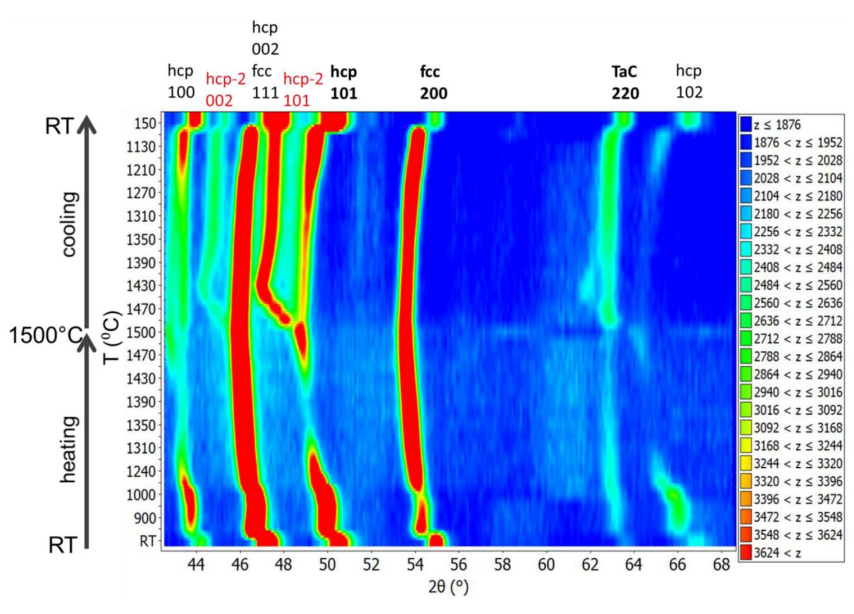

Fig. 3. Temperature dependence of the diffractograms for the sample with 0.4 at.\% B (CoRe-TaC-09y-04B). The important reflections are marked. The scale on the left denotes the temperature on heating (bottom part) and cooling (upper part). The color-map intensity levels (the color range shown in the right) were selected in such a way that also the weaker reflections are clearly visible. The splitting of the hcp phase peak 101 at $1500^{\circ} \mathrm{C}$ is clearly visible.

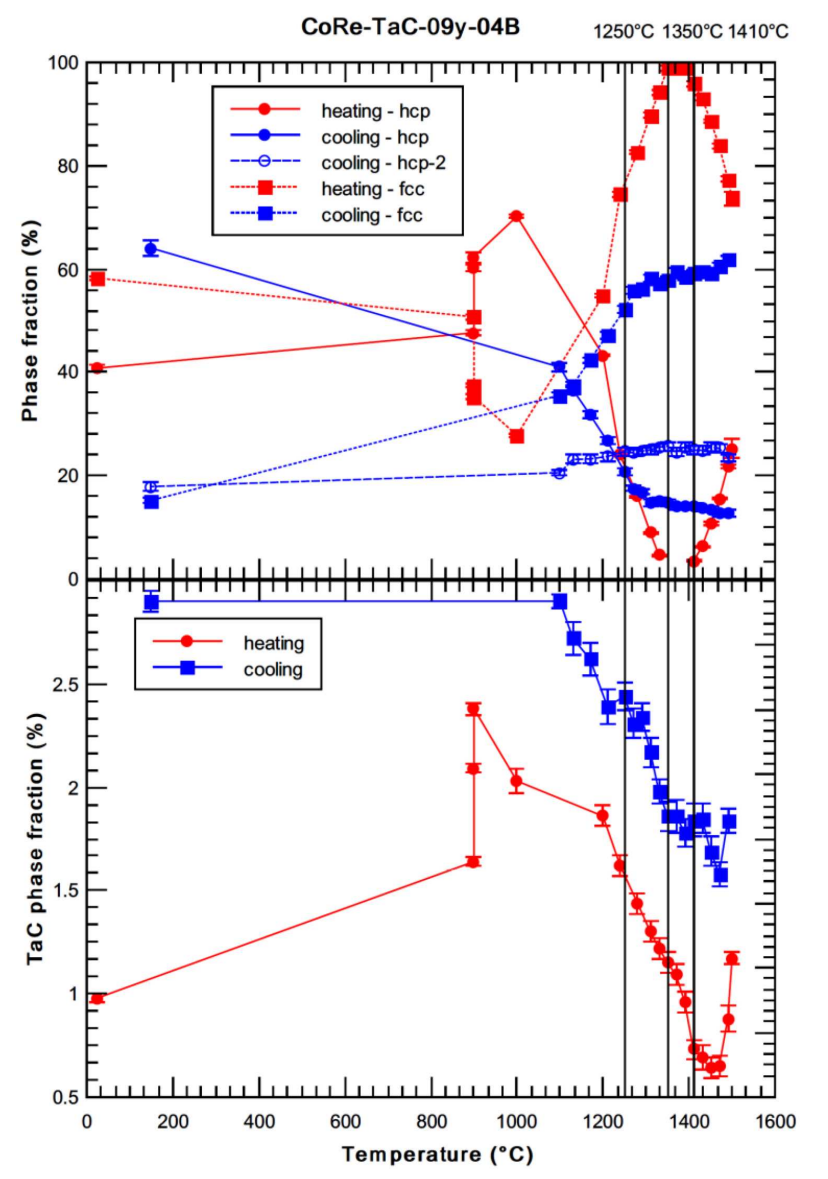

Fig. 4. Temperature dependence of the phase content for the 0.4 at.\% B sample (CoRe-TaC-09y-04B). Upper part of the figure shows hcp and fcc matrix phases while the bottom part shows $\mathrm{TaC}$ content. hcp phase first disappears at $1350^{\circ} \mathrm{C}$; however, it surprisingly comes back at still higher temperature of $1410^{\circ} \mathrm{C}$. Such effect was previously never observed in other Co-Re alloys and will be discussed later in this paper.

When the temperature is still increased to $1500^{\circ} \mathrm{C}$, the hcp matrix phase splits into two phases with hcp structure but different unit cell size (the second one is denoted hcp-2). Such splitting was previously observed also in $\mathrm{Cr}$ containing $\mathrm{Co}-\mathrm{Re}$ alloys [5] with high boron content. It indicates that presence of larger amount of boron promotes the hcp phase splitting. The mechanism was examined and explained in [6] suggesting that massive (boron-assisted) sublimation of Co and Cr from the sample surface occurs during the heating under vacuum. Due to this sublimation, the surface layer of the sample is enriched in Re, and the matrix near the surface has thus an hcp phase with significantly different lattice parameters than in the center of the sample. The sublimation is clearly promoted by the B content, as it is not observed in alloys without boron or with low boron content [6]. The Co sublimation is massive, as it leads to a depletion (not immediately equilibrated by the diffusion flow from the center of the sample) of a macroscopic part of the sample near the surface even from the point of view of a bulk-characterizing technique as ND (i.e. the layer thickness is certainly above $50 \mu \mathrm{m}$ ).

Our results indicate that such effect takes place also in the alloy without chromium, and the Co sublimation is clearly promoted by boron, as it is observed for higher boron concentration ( 0.4 at.\% boron) while it is absent for 0.1 at. $\%$ boron sample as well as for the sample without boron.

The result of the Rietveld refinement of phases in the CoRe-TaC-09y-04B sample is depicted in Fig. 4. The upper part of the figure shows the hcp and fcc matrix phases evolution while the bottom part shows the TaC volume fraction. From Figs. 3 and 4, it is seen that the hcp-2 phase appeared during the $80 \mathrm{~min}$ hold at $1500^{\circ} \mathrm{C}$. On cooling, hcp- 2 phase fraction remains nearly constant while the fcc phase continuously transforms to hcp matrix phase. Also, hcp-2 lattice parameters initially strongly vary at the begining of cooling and then stabilize at $1430^{\circ} \mathrm{C}$.

During heating, $\mathrm{TaC}$ in CoRe-TaC-09y-04B sample behaves in a very similar way as in CoRe-TaC-09y-01B. During cooling, it is influenced by the hcp phase reappearance and splitting at high temperatures, which promotes also the $\mathrm{TaC}$ carbide volume fraction increase (Fig. 4). At RT after the thermal cycle, the volume fraction of $\mathrm{TaC}$ is nearly $3 \%$.

\subsection{Comparison of 0.1 and 0.4 at.\% boron samples with the sample without boron addition}

In Fig. 5a, results of the Rietveld quantitative phase analysis for hcp matrix phase in samples with 0.1 and 0.4 at.\% boron, as well as for the hcp matrix phase in sample without boron (but with otherwise identical alloy composition) are depicted for the high-temperature 

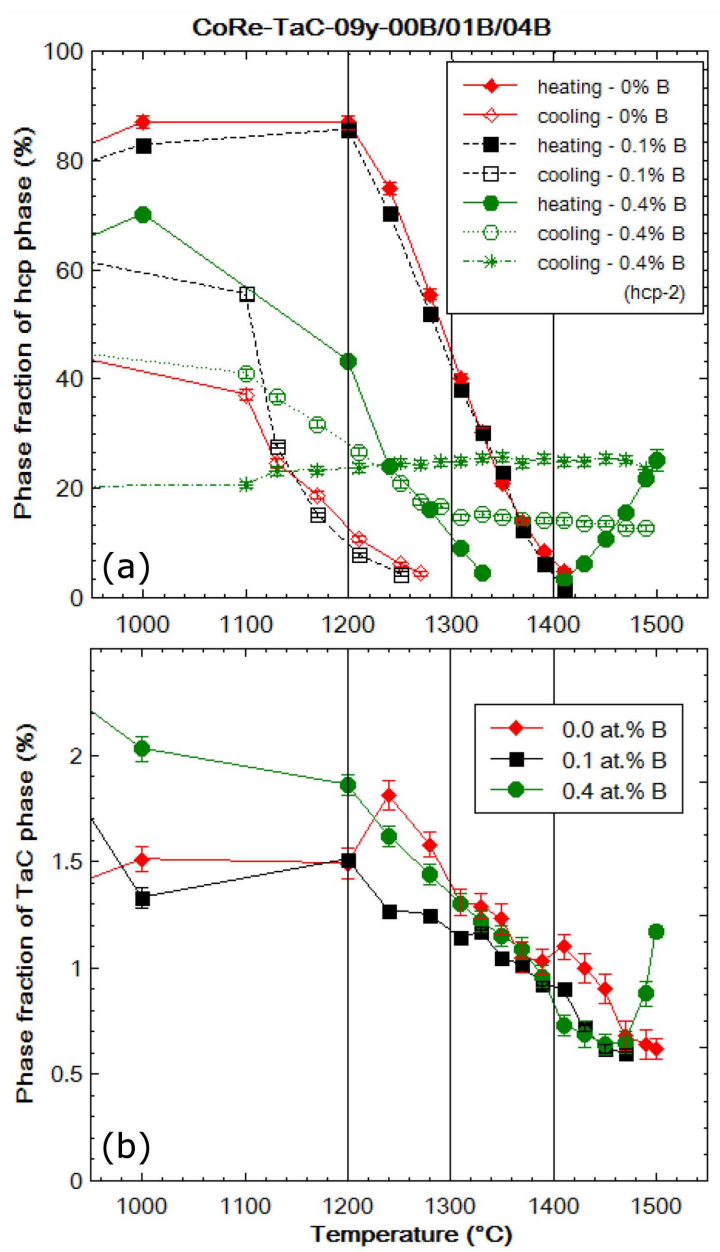

Fig. 5. Temperature dependence of (a) the hcp matrix phase content during heating and cooling, and (b) TaC content during heating for $0,0.1$, and 0.4 at. $\% \mathrm{~B}$ samples.

region. It can be seen that the sample without boron and the 0.1 at.\% boron sample show very similar behavior for the hcp-to-fcc transformation and hysteresis. On the other hand, the 0.4 at.\% boron sample differs significantly, and the phase transformation during heating occurs at about $100 \mathrm{~K}$ lower temperature.

Comparison of the $\mathrm{TaC}$ volume fraction in the temperature range $1200-1400^{\circ} \mathrm{C}$ (see Fig. 5b) shows rather similar volume fractions and its evolution with temperature during heating for all three samples $(0,0.1$, and 0.4 at. $\%$ boron).

\subsection{Further studies of the 0.4 at.\% boron alloy}

In order to assess the reason for the hcp phase behavior at HT, additional measurements were carried out in the follow-up experiment on 0.4 at.\% B alloy. Figure 6 displays the evolution of diffraction profiles with temperature in the thermal cycle up to $1470^{\circ} \mathrm{C}$ with long hold at this temperature for the sample CoRe-TaC-09y04B No.1.

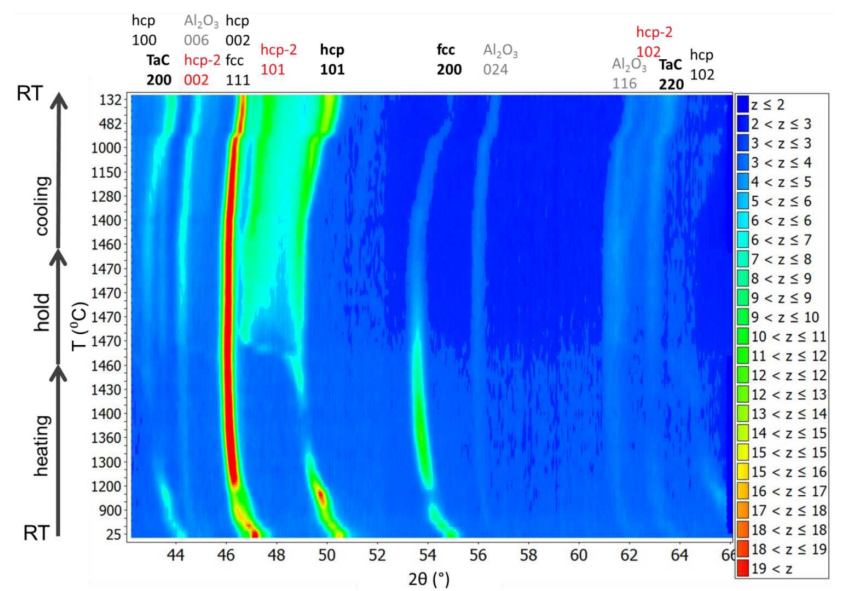

Fig. 6. Temperature dependence of the diffractograms for the sample with 0.4 at.\% B (CoRe-TaC-09y04B_No.1) held for $17 \mathrm{~h}$ at $1470{ }^{\circ} \mathrm{C}$. The important reflections are marked. The scale on the left denotes the temperature on heating (bottom part) and cooling (upper part). The color-map intensity levels (the color range shown in the right) were selected in such a way that also the weaker reflections are clearly visible. Three of the reflections are parasitic reflections from an alumina sample holder $\left(\mathrm{Al}_{2} \mathrm{O}_{3} 006,024,116\right)$.

This experiment confirmed the hcp phase splitting. In this case it occurred already at the beginning of the hold at $1470^{\circ} \mathrm{C}$. The same explanation as for the CoRe-TaC09y-04B sample described above can be applied. Moreover, the hcp and hcp-2 phases are connected by the layer with continuously changing lattice spacing between its hcp and hcp- 2 values. This can be deduced from the 101 reflections of both hexagonal phases (Fig. 6), which were connected by a continuous range of increased intensity in the diffractogram after several hours hold at $1470{ }^{\circ} \mathrm{C}$. It indicates a continuous change of lattice parameter in the hcp phase in a macroscopic region of the alloy at high temperatures.

The evolution of integral intensities of the important reflections is displayed in Fig. 7. Also for this sample, hcp phase reappears at $1400^{\circ} \mathrm{C}$ (see 101 hcp peak in Fig. 6 or Fig. 7). It is worth noticing that TaC intensity is zero or nearly zero around $1400^{\circ} \mathrm{C}$ during heating, i.e. in the moment when hcp matrix phase starts to re-appear. TaC peak starts to grow again at $1440{ }^{\circ} \mathrm{C}$, i.e. only after the hcp peak intensity increased considerably.

The evolution of background intensity, another important indicator, is displayed in Fig. 8 for the angles $57.5-59.5^{\circ}$, where no diffraction peak is present in the whole temperature range. The background intensity clearly dropped significantly when the hold temperature of $1470{ }^{\circ} \mathrm{C}$ was reached. This indicates reduction of the Co concentration in the volume studied as Co causes strong incoherent scattering of neutrons and is responsible for the majority of the observed background intensity [6]. This corroborates the massive Co sublimation from the surface layer of the alloy at $1470^{\circ} \mathrm{C}$ causing 


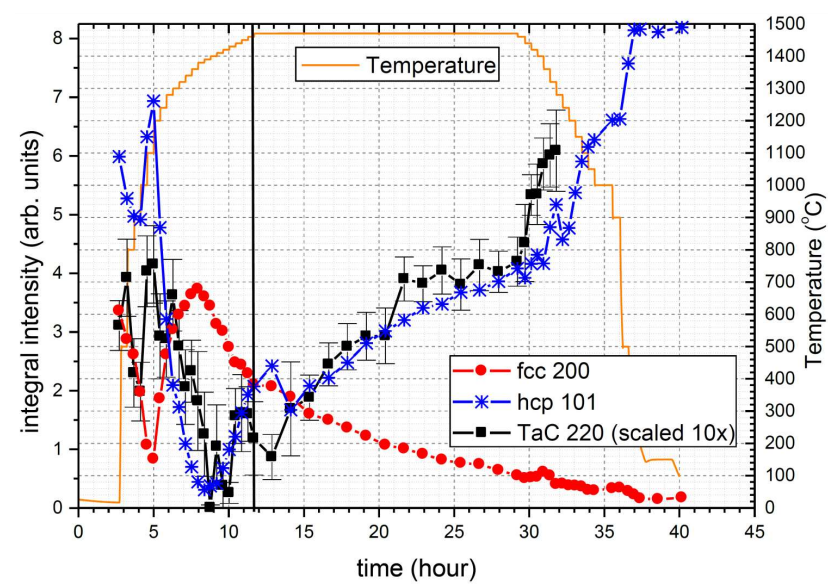

Fig. 7. Evolution of integral intensities of important reflections for 0.4 at.\% B sample CoRe-TaC-09y04B_No.1 held for $17 \mathrm{~h}$ at $1470{ }^{\circ} \mathrm{C}$. The used temperature profile is displayed as well. TaC 220 reflection intensity after cooling below $1300^{\circ} \mathrm{C}$ is not displayed as it overlaps with the $102 \mathrm{hcp}-2$ reflection in that temperature region.

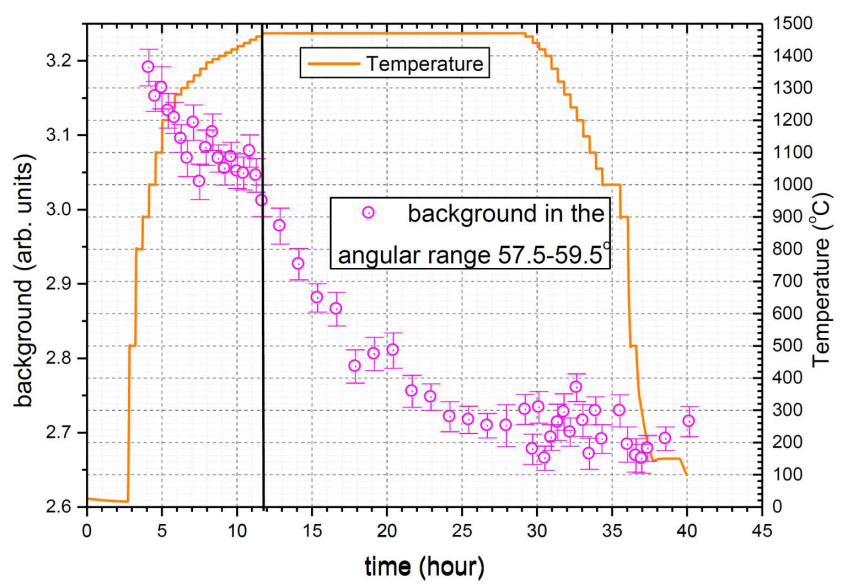

Fig. 8. Evolution of the background intensity for the 0.4 at.\% B sample CoRe-TaC-09y-04B_No.1.

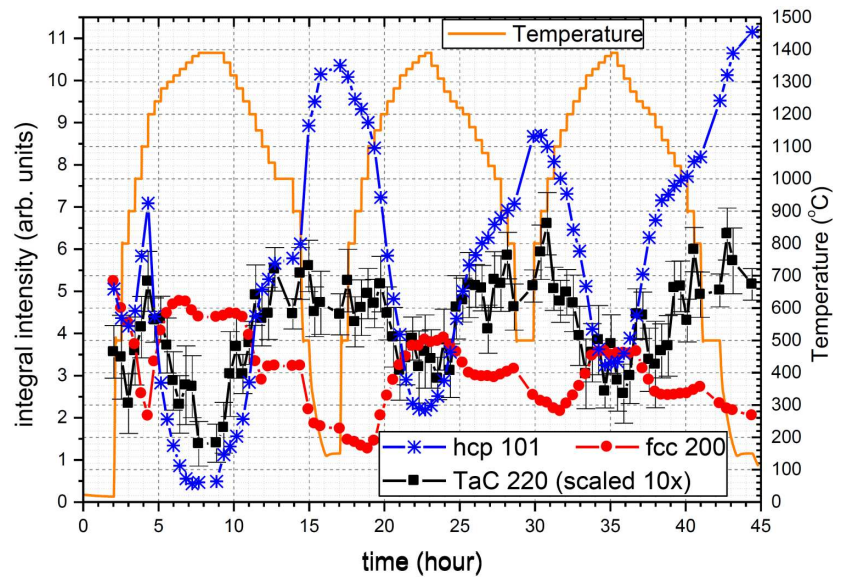

Fig. 9. Evolution of integral intensities of important reflections for the 0.4 at.\% B sample CoRe-TaC-09y04B_No.2 during cycling up to the temperature of $1390^{\circ} \mathrm{C}$. The temperature profile used is displayed as well. the hcp phase splitting. During the hold at $1470^{\circ} \mathrm{C}$, the background decrease slows down. The slowdown can be possibly caused by a formation of a film on the surface which hinders sublimation of Co. Other reason can be the Co depletion of the region in the immediate vicinity of surface and insufficient diffusion of Co from the bulk of the sample.

It can be nevertheless seen in Fig. 8 that the background decreased also at lower temperatures (900$1470{ }^{\circ} \mathrm{C}$ ), although not so fast. The decrease of the background can again indicate the Co sublimation, albeit with much lower rate.

In the last experiment with 0.4 at.\% B alloy (sample CoRe-TaC-09y-04B_No.2), the evolution of high boron alloy structure was tested during cycling without influence of the hcp-phase splitting. Therefore, three cycles were performed only up to the temperature of $1390^{\circ} \mathrm{C}$. Figure 9 shows evolution of integral intensities of the important peaks of the phases present during cycling.

First, it can be deduced from the data that no massive sublimation of Co occurred up to $1390^{\circ} \mathrm{C}$ as no hcp phase split is observed.

The evolution of phases during cycling is qualitatively the same in each cycle, except the fact that there is - with increase of number of cycles - increasing hcp amount at the highest tested temperature of $1390^{\circ} \mathrm{C}$. The fcc phase peak 200 intensity evolves at $1390^{\circ} \mathrm{C}$ during cycling in an opposite direction than the hcp peak intensity. Moreover, the hcp peak 101 increases during $1.5 \mathrm{~h}$ hold at $1390^{\circ} \mathrm{C}$ which was performed during the first cycle.

That means that the hcp phase re-appears not only at 1410 and $1400^{\circ} \mathrm{C}$ as observed previously for the samples CoRe-TaC-09y-04B and CoRe-TaC-09y-04B No.1, but also at $1390^{\circ} \mathrm{C}$ after $1.5 \mathrm{~h}$ hold, and probably would also appear at still lower temperatures for sufficiently long hold times.

The TaC peak intensity decreases significantly on heating above $1250^{\circ} \mathrm{C}$. It comes back when cooling and its volume fraction is stable at temperatures below $1200^{\circ} \mathrm{C}$.

Interesting point is also that the transformation reaction fcc to hcp slows down during cooling in the temperature range $1200-800^{\circ} \mathrm{C}$. It is also connected with slowing down the $\mathrm{TaC}$ volume fraction increase.

In Fig. 10, the background intensity for the angular region $57.5-59.5^{\circ}$ is displayed for the sample CoRe-TaC09y-04B_No.2. A decrease of background during all three thermal cycles indicates a decrease of incoherent scattering. It is getting slower at longer exposure times. Although the statistical errors are large, it seems that the background decrease is the fastest around the highest applied temperature of $1390{ }^{\circ} \mathrm{C}$.

\subsection{The cause of the hcp-matrix re-appearance around $1400^{\circ} \mathrm{C}$}

After the hcp phase disappears at $1350^{\circ} \mathrm{C}$ in the CoReTaC-09y-04B sample (Fig. 3), it comes back at still higher temperature of $1410^{\circ} \mathrm{C}$. This feature was confirmed in a follow-up experiment with the CeRe-TaC- 


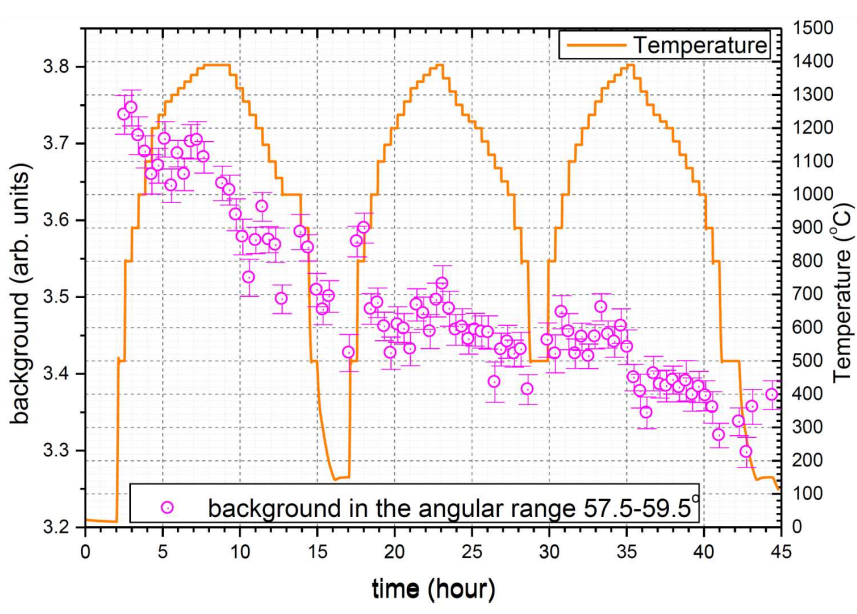

Fig. 10. Evolution of background intensity for 0.4 at.\% B sample CoRe-TaC-09y-04B No.2.

09y-04B_No.1 sample where the hcp phase started to reappear at $1400^{\circ} \mathrm{C}$. This effect was previously never observed in Co-Re alloys and is rather surprising since hcp is the thermally stable Co matrix phase at low temperature. Therefore, this deserves a more detailed investigation and explanation

The following 3 hypotheses were put forward for explaining this effect:

1. In the matrix, a depletion of fcc-stabilizing elements Ta, C [19] or B could occur through binding them to some compound at the temperature of $1410^{\circ} \mathrm{C}$. Such compound could be in principle the $\mathrm{TaC}$ carbide, boron carbide $\mathrm{B}_{4} \mathrm{C}$, tantalum borides or cobalt borides. The last mentioned option would also remove Co from the matrix, which would lead to a relative enrichment of the matrix by Re (which is hcp stabilizer).

2. There could be a sublimation of fcc stabilizing elements Ta, C, or B from the matrix. Transformation hcp to fcc should then be shifted to higher temperatures.

3. There could be a sublimation of Co from the matrix, which would lead to a relative enrichment of the matrix by Re (which is hcp stabilizer).

Ad (i): First sub-option is the TaC re-formation above $1400^{\circ} \mathrm{C}$. However, the $\mathrm{TaC}$ volume still slightly decreases when hcp matrix phase is coming back, and TaC starts to increase only at $1490{ }^{\circ} \mathrm{C}$. This fact was confirmed in a follow-up experiment with the alloy CoReTaC-09y-04B No.1 intended to let grow possible small $\mathrm{TaC}$ precipitates (if they would exist) in the temperature range $1400-1470{ }^{\circ} \mathrm{C}$ during relatively slow temperature increase. No such TaC precipitation was, however, observed. Second sub-option is boron carbide, tantalum borides, or cobalt borides formation. No peaks of these phases were, however, observed. The option (i) as whole is thus very unlikely.
Ad (ii): A sublimation of fcc stabilizing elements Ta or $\mathrm{C}$ from the matrix would mean that there would be less of these elements for the formation of $\mathrm{TaC}$ on cooling. This was, however, not observed. The amount of $\mathrm{TaC}$ was even higher after thermal cycle with the sample CoReTaC-09y-04B (see e.g. in Fig. 4 the volume fraction of $\mathrm{TaC}$ at $1200^{\circ} \mathrm{C}$ on heating and on cooling). The followup experiment with the CoRe-TaC-09y-04B_No.2 sample which underwent three thermal in situ cycles up to $1390^{\circ} \mathrm{C}$ (i.e. without splitting of the hcp phase) showed that there is a stable amount of TaC carbides at RT after each cycle (see Fig. 9). A strong sublimation of B is also unlikely as high amount of boron needs to be present to assist the massive sublimation of $\mathrm{Co}$ at $1500^{\circ} \mathrm{C}$, which was observed for CoRe-TaC-09y-04B sample, and also for CeRe-TaC-09y-04B_No.1 at $1470^{\circ} \mathrm{C}$ in the follow-up experiment. Moreover, if the hcp re-appearance would be caused by B sublimation, then a very significant amount of boron would have to be sublimated. A slight B sublimation could not be responsible for so large shift of the transformation temperature of the matrix: only if the boron concentration would decrease by sublimation from 0.4 at. $\%$ B to 0.1 at. $\%$ B, then the matrix transformation temperature would shift so significantly that it would enable formation of the hcp phase at $1410^{\circ} \mathrm{C}$ (see Fig. 5). The option (ii) as whole is thus also unlikely.

Ad (iii): A slow sublimation of Co from the sample surface would cause that the sample is enriched in Re which is hcp stabilizer and it will promote the backtransformation $\mathrm{fcc} \rightarrow$ hcp even at higher temperatures. Nevertheless, sublimation of Co would need to be rather slow. Because two different lattice parameters (for the surface region and for the bulk) are not seen at temperatures around $1400^{\circ} \mathrm{C}$, the sublimation from the surface layer would need to be compensated by the diffusion of Co from the sample center towards the surface. This seems to be possible. Moreover, one should keep in mind that there is no $\mathrm{Cr}$ in the samples and hence there is no protective oxide layer formation at the surface. Furthermore, cobalt has the lowest equilibrium vapor pressure temperature out of all constituents in the alloy (i.e. Co, Re, Ta, C, B). High-vacuum furnace $\left(10^{-5}\right.$ $10^{-6}$ mbar) was used for the experiment. Such equilibrium vapor pressure corresponds to sublimation temperatures around $1100{ }^{\circ} \mathrm{C}$ for pure Co. Co sublimation at high temperatures during the present experiment was thus likely.

The evolution of phases observed in boron containing Co-Re-Ta-C alloys at HT in the ND experiments can be explained by Co sublimation at temperatures around $1400^{\circ} \mathrm{C}$. The Co hcp phase (the low temperature Co allotrope) re-appears at $1390^{\circ} \mathrm{C}$ (Fig. 9). The hcp phase also increases progressively at $1390^{\circ} \mathrm{C}$ with the number of cycles (Fig. 9). It indicates an irreversible change (sublimation) rather than a process induced by some minority phase transformations (which is expected to be at least partly reversible during the thermal cycling). Slow Co sublimation fits to this frame. Another supporting point 
is the background intensity evolution, mainly caused by incoherent scattering from Co. It decreases during the hold or thermal cycling at high temperatures (Figs. 8 and 10). The Co sublimation (which enriches the matrix in hcp-stabilizer Re) explains the observation, i.e. the re-appearance of hcp matrix phase around $1400^{\circ} \mathrm{C}$.

\section{Conclusions}

The hcp to fcc transformation of the Co-solid solution matrix and the TaC phase evolution was investigated in Co-Re-Ta-C alloys with varying boron addition.

All the investigated samples contained metastable fcc Co-solid solution matrix phase at RT resulting from argon quenching after ST. It is transformed to stable hcp Co-solid solution matrix by in situ heating to $900{ }^{\circ} \mathrm{C}$. Further temperature increase induces allotropic transformation of hcp to fcc Co-solid solution matrix phase at temperatures above $1100^{\circ} \mathrm{C}$. The phase transformation is completed at $1420^{\circ} \mathrm{C}$ for 0.1 at.\% B alloy and at $1350{ }^{\circ} \mathrm{C}$ for 0.4 at.\% B alloy. When cooling, a hysteresis of about $160 \mathrm{~K}$ is observed in the back-transformation fcc $\rightarrow$ hcp. The alloys without boron and with 0.1 at.\% boron provide very similar result for the hcp $\rightarrow$ fcc transformation and hysteresis.

For 0.1 at.\% $\mathrm{B}$ alloy, the evolution of matrix phases in the two subsequent thermal cycles up to $1500^{\circ} \mathrm{C}$ is not significantly different. Nevertheless, the TaC content is slightly higher after the second cycle $(2.2 \%$ compared to $1.7 \%$ ).

Neutron diffraction showed that boron addition has no significant influence on the $\mathrm{TaC}$ volume fraction during heating to high temperatures. In all alloys $(0,0.1$, and 0.4 at.\% B), a strong decrease of $\mathrm{TaC}$ volume fraction was observed above $1300^{\circ} \mathrm{C}$. Nevertheless, TaC has a significant volume fraction up to that temperature and can be thus effective for strengthening. Higher affinity of $\mathrm{TaC}$ for precipitation in the hcp phase (rather than in the fcc phase) is also confirmed.

Higher boron concentration (0.4 instead of 0.1 at.\% B) shifted the transformation temperature hcp $\rightarrow$ fcc down by approximately $100 \mathrm{~K}$. However, hcp reappears at still higher temperatures of about $1410^{\circ} \mathrm{C}$. This effect was explained by slow cobalt sublimation from the sample, which enriched the matrix with the hcp-stabilizing element Re.

At still higher temperatures $\left(1470-1500^{\circ} \mathrm{C}\right)$ boron promoted fast sublimation of Co in high boron concentration (0.4 at.\% B) alloy, which leads to the formation of hcp-2 matrix phase in the surface layer of the alloy. Similar splitting of the Co-solid solution matrix hcp phase is not observed in case of low boron concentration (0.1 at.\%) alloy.

The ND experiment showed that small amount of boron addition ( 0.1 at.\% B) has neither significant influence on matrix transformation/hysteresis nor on $\mathrm{TaC}$ content during heating to HT. However, higher amount of boron (0.4 at.\% B) has a significant influence on matrix transformation temperature (lowers it by about $100 \mathrm{~K}$ ) and, moreover, boron promotes a massive Co sublimation at very high temperatures in high vacuum furnace. It should be stressed, nevertheless, that vacuum is not a standard turbine operation condition, and that the high-temperature components are regularly protected by coatings.

\section{Acknowledgments}

The authors would like to thank the German Research Foundation (DFG) for providing the financial support for the joint Co-Re alloy development project at TU Braunschweig and TU Münich (RO 2045/31-1 and GI 242/4-1 respectively). The authors thank FRM-II Garching, Germany, for providing the beamtime for neutron scattering measurements, and CANAM (NPI Rež, Czech Republic, MŠMT infrastructural project No. LM2015056), for enabling neutron diffraction data evaluation. P. Strunz, P. Beran and G. Farkas acknowledge support by GACR project no. $14-36566 \mathrm{G}$.

\section{References}

[1] J. Rösler, D. Mukherji, T. Baranski, Adv. Eng. Mater. 9, 876 (2007).

[2] D. Mukherji, J. Rösler, P. Strunz, R. Gilles, G. Schumacher, S. Piegert, Int. J. Mater. Res. 102, 1125 (2011).

[3] D. Mukherji, P. Strunz, R. Gilles, L. Karge, J. Roesler, Kovove Mater. Metall. Mater. 53, 287 (2015).

[4] D. Mukherji, J. Roesler, M. Krueger, M. Heilmaier, M.-C. Boelitz, R. Voelkl, U. Glatzel, L. Szentmiklosi, Scr. Mater. 66, 60 (2012).

[5] P. Strunz, D. Mukherji, P. Beran, R. Gilles, L. Karge, M. Hofmann, M. Hoelzel, J. Rösler, G. Farkas, Met. Mater. Int. 24, 943 (2018).

[6] P. Beran, D. Mukherji, P. Strunz, R. Gilles, L. Karge, M. Hofmann, M. Hoelzel, J. Rösler, G. Farkas, Metals 8, 621 (2018)

[7] D. Mukherji, M. Klauke, P. Strunz, I. Zizak, G. Schumacher, A. Wiedenmann, J. Rösler, Int. J. Mater. Res. 101, 340 (2010).

[8] R. Gilles, P. Strunz, D. Mukherji, M. Hofmann, M. Hoelzel, J. Roesler, J. Phys. Conf. Series 340, 012052 (2012).

[9] D. Mukherji, J. Rösler, J. Wehrs, P. Strunz, P. Beran, R. Gilles, M. Hofmann, M. Hoelzel, H. Eckerlebe, L. Szentmiklósi, Z. Mácsik, Metall. Mater. Trans. 44A, 22 (2013).

[10] D. Mukherji, R. Gilles, L. Karge, P. Strunz, P. Beran, H. Eckerlebe, A. Stark, L. Szentmiklosi, Z. Mácsik, G. Schumacher, I. Zizak, M. Hofmann, M. Hoelzel, J. Rösler, J. Appl. Crystallogr. 47, 1417 (2014).

[11] P. Strunz, D. Mukherji, R. Gilles, U. Gasser, P. Beran, G. Farkas, M. Hofmann, L. Karge, J. Rösler, Acta Phys. Pol. A 128, 684 (2015).

[12] R. Gilles, D. Mukherji, L. Karge, P. Strunz, P. Beran, B. Barbier, A. Kriele, M. Hofmann, H. Eckerlebe, J. Rösler, J. Appl. Crystallogr. 49, 1253 (2016). 
[13] L. Karge, R. Gilles, D. Mukherji, P. Strunz, P. Beran, M. Hofmann, J. Gavilano, U. Keiderling, O. Dolotko, A. Kriele, A. Neubert, J. Rösler, W. Petry, Acta Mater. 132, 354 (2017).

[14] D. Mukherji, P. Strunz, R. Gilles, M. Hofmann, F. Schmitz, J. Rösler, Mater. Lett. 64, 2608 (2010).

[15] D. Mukherji, P. Strunz, S. Piegert, R. Gilles, M. Hofmann, M. Hoelzel, J. Roesler, Metall. Mater. Trans. 43A, 1834 (2012).

[16] P. Beran, D. Mukherji, P. Strunz, R. Gilles, M. Hofmann, L. Karge, O. Dolotko, J. Rösler, Met. Mater. Int. 22, 562 (2016).
[17] M. Hofmann, R. Schneider, G.A. Seidl, J. Kornmeier, R. Wimpory, U. Garbe, H.G. Brokmeier, Physica B Condens. Matter 385-386, 1035 (2006).

[18] J. Rodríguez-Carvajal, Physica B Condens. Matter 192, 55 (1993).

[19] A.M. Beltran, Cobalt-Base Alloys, in Superalloys II, Eds. C.T. Sims, N.S. Stoloff, W.C. Hagel, Wiley, New York 1987, p. 141 